\title{
Evaluation of the impact of strategic staff planning in a university using a MILP model
}

\author{
R. de la Torre* \\ Department of Management/ETSEIB, \\ Universitat Politècnica de Catalunya, \\ Av. Diagonal 647, 7th Floor, 08028 Barcelona, Spain \\ Email: maria.rocio.de.torre@upc.edu \\ *Corresponding author
}

\begin{abstract}
A. Lusa
Department of Management/IOC/ETSEIB, Universitat Politècnica de Catalunya,

Av. Diagonal 647, 11th floor, 08028 Barcelona, Spain

Email: amaia.lusa@upc.edu

\section{Mateo}

Department of Management/ETSEIB, Universitat Politècnica de Catalunya,

Av. Diagonal 647, 7th Floor, 08028 Barcelona, Spain

Email: manel.mateo@upc.edu
\end{abstract}

\begin{abstract}
A mathematical model for optimising the strategic staff planning in universities is used to analyse the impact of different personnel and academic policies on the strategic staff plan, considering a preferable staff composition. The personnel policies are evaluated allowing or not the dismissals of permanent workers; the ratio of internal promotion for workers and the personnel budget. The academic policies are tested through the impact of different demand trends. Addressing the specificities of the university, the optimisation model considers not only economic criteria, i.e., personnel costs, but also other factors related to the fulfilment of the required service level and the achievement of a preferable workforce composition. Several computational scenarios are used, based on real data from the Universitat Politècnica de Catalunya (Barcelona, Spain). The results show the adjustment to the preferable workforce composition through the available mechanisms (dismissals, hiring and internal promotions). [Received: 12 June 2015; Revised: 24 November 2015; Revised: 24 July 2016; Accepted: 7 December 2016]
\end{abstract}

Keywords: strategic staff planning; long-term staff planning; university; MILP.

Reference to this paper should be made as follows: de la Torre, R., Lusa, A. and Mateo, M. (xxxx) 'Evaluation of the impact of strategic staff planning in a university using a MILP model', European J. Industrial Engineering, Vol. X, No. Y, pp.000-000. 
Biographical notes: Rocio de la Torre received her degree in Industrial Engineering from the School of Industrial Engineering of Barcelona, Universitat Politècnica de Catalunya (UPC) in 2011, and a PhD in Business and Management Administration from the UPC in 2015. Her PhD thesis focused on the research of methods for the strategic capacity planning in public universities. She has been conducting teaching on subjects related to the industrial organisation from 2011. Her research activities are focused on the development of optimisation methods to solve strategic planning in knowledge intensive organizations. Also, she is involved in research activities on supply chain design.

Amaia Lusa is a Professor University at the Department of Business Administration, Universitat Politècnica de Catalunya, UPC. She teaches at the School of Engineering of Barcelona (ETSEIB) in quantitative methods and engineering subjects about organisation and logistics. Her research at the Institute for Organization and Control of Industrial Systems of the UPC focuses on the development and application of quantitative techniques for solving the planning of production systems and logistics, as well as on the methodologies for the design of instruments for the detection and elimination of discrimination based on gender.

Manel Mateo is a Professor of Industrial Engineering and Operations Research at the Universitat Politècnica de Catalunya (UPC), where he is a member of the Business Administration department and the Engineering School of Barcelona (ETSEIB). He has a degree in Engineering and $\mathrm{PhD}$ from the UPC. His research activities, IOC research group (UPC), are focused on the development and application of techniques to solve productive and logistic systems design, planning and scheduling problems.

\section{Introduction}

In many European countries, both public and private higher education institutions (HEIs) are facing new pressures in an increasingly business oriented environment. These pressures are imposing great demands on organisations to need learning how to develop strategies and reaction protocols for future challenges. Challenges, in turn, mainly set by the so-called Bologna process, referring to several aspects such as the reformulation and unification of academic degrees in Europe; the change in research field through the European Research Area; the definition of new national mechanisms for managing national resources (public funding) for teaching and research activities; the increasing emphasis on university-industry relationship; and the promotion of market oriented activities, especially by patents and academic entrepreneurship (Mckelvey and Holmen, 2009).

During the last decades, HEIs have been adapting some management strategies inspired in business world. These strategies propose to determine, in a long-term horizon, the quantity and type of resources for an organisation considering not only economic criteria but also other aspects of different nature. The strategic capacity plan is regarded as a key element in the design and viability for an organisation; however, so far formalised procedures for its determination are just focused in manufacturing industry, noting very few cases for the service sector (e.g., supermarkets, call centres and so on). This idea was pointed out by Machuca et al. (2006) and Roth and Menor (2003), as they 
warned a gap between the growing importance of management in the service sector (including the universities) and the number of studies in literature. In addition, Lillis (2006) claimed that available literature does not provide a standardised methodology to determine the effectiveness of the strategic capacity plan neither a procedure for measuring and analysing the organisational learning of the process. Further, an additional problem with the strategic capacity planning in the service sector, also in HEIs, is the widespread inability to implement its plan, once it is developed and approved by the institutional government (Rowley and Sherman, 2001).

In this context, several studies conducted in HEIs (Clark, 2003, 1998; Lounsbury, 2001; Shattock, 2003; Agasisti et al., 2008) indicate that the number of strategic practices is increasing and diversifying. This evolution has been influenced as a response to external pressures for a better accountability, which in strategic terms imply answering strategic problems, as well as teaching and research quality. Martinez and Wolverten (2009) noted that considering those many changes in higher education the universities are facing, they would better adopt new management strategies; otherwise, they would not be ready to apply changes in academic and financial policies when necessary.

Therefore, strategic capacity planning in universities is a hot topic and very timely, as it will take changes in current funding, human resources (Santiago et al., 2009) and academic policies. As some authors argue, such as Hunt et al. (1997), the strategic capacity planning will allow universities a better use of the resources, and thus, they will achieve a greater institutional success (greater international projection, better academic and innovative environment, etc.). Titova and Shutov (2014) present a predictive model for the workforce size considering aspects as the quality of the educational services, the level of development of research activities, the public image of the university as well as the financial issues. Recently, de la Torre et al. (2016) propose a methodology to deal with the strategic staff planning in public universities. The proposed methodology includes a mathematical model for optimising the university workforce in a long-term horizon. The paper briefly tests its performance for optimising the long-term planning according to a preferable workforce composition. The model is evaluated through few sensitivity analyses on input data, only university circumstances, personnel costs and worker's capacity.

Coming back to the planning decisions, since the early production planning model of Holth et al. (1960), which considered personnel hiring and dismissal in a very simple way applied to the manufacturing industry, few authors have dealt with similar problems. For instance, Singhal (1992) adapted the initial work carried out by Holth et al. (1960) to be suitable for application in large problems, since it proposes an easy and efficient non-iterative quadratic cost function instead of the iterative linear cost function proposed in the former paper. Further, some authors as Gans and Zhou (2002) have dealt with similar problems in simple service sector systems by proposing a model for personnel hiring and dismissal with constrains related to the turnover and the training process in new workers. Based on this, Song and Huang (2008) present a model with homogeneous workers in different units in which the main optimisation criterion is to minimise the personnel cost. Ahn et al. (2005) propose a model, but considering heterogeneous workers. Other authors, as Corominas et al. (2012) propose a model for an aggregate planning problem including a learning period, but the transfers between categories (promotions within a given pathway) are not included there. 
So from the above description of the state of the art, and to the best of our knowledge, there are no studies in the scientific literature to deal with the determination of the size and composition of the staff in a public university, except de la Torre et al. (2016). But none of them analyses the consequences of the strategic policies taken beforehand by universities. For instance, they have influence, besides the expertise and the fixed service level, on a preferable workforce composition. This optimisation criterion complements the economic ones. Moreover, the regulations on hiring, dismissals, promotions and the particular characteristics of a high-qualified employee's organisation should be taken into account.

Further deeping in the staff planning in universities, and based on the above mentioned work, the main contribution of this paper is the development of a set of analyses around the impact of different strategic decisions in the determination of the strategic staff plan for a public university, thus leading to novel managerial insights. These strategic decisions regard personnel policies, academic policies, as well as the adoption of one preferable workforce compositions among several. So, the proposed analyses aim to prove the potential of the model for decision makers on long-term staff planning according to the trends in their institutions, as well as to get useful managerial insights.

The paper is organised as follows: Section 2 deals with the problem description and the scope of the article; Section 3 presents the mixed integer linear programming (MILP) model for dealing with the problem; a numerical example is described in Section 4; Section 5 gives details on an analysis of the impact of different strategic decisions. Finally, the conclusions are exposed in Section 6.

\section{Problem description and scope of the article}

The determination of the strategic staff plan is challenged by several inherent and exogenous aspects characterising the university and its activities, which are briefly presented below.

Two defining characteristics of the university are that its core activity is the transfer of knowledge and its main resource is the academic staff. Universities are usually organised in departments or units, according to the staff expertise. In turn, the workforce at each department is structured in several categories, according to their skills and contract.

The tasks that can be performed are teaching, research, technology transfer and management, and worker's capacity depends on at which category they belong. This capacity changes when someone is promoted to higher categories. It happens once he/she obtains the required merits and the organisation provides a new spot in the aforementioned upper category. Usually, workers can be further classified in full time and part time ones. Part time lecturers are usually hired only for teaching purposes, what means that research, technology transfer and management are tasks not included in their competences. These workers provide students with business experience, thus complementing their education. The proportion hold by these lecturers in university can be bounded by the government and is subjected to some strategic decisions (e.g., hiring and dismissals). 
So at the end, the university holds a heterogeneous workforce and this has to be organised in the strategic staff plan taking into account also other exogenous and time varying conditions as government laws, funding policies, and economic resources and so on. As a result, for the setting up process of the strategic staff plan, other criteria apart from the economic should be also considered. In this sense, as de la Torre et al. (2016) propose the evaluation criteria for these strategic decisions can be a combination of: economics (maximising the profit or minimising the total cost), a preferable staff composition and the service level given to students. Adopting a set of criteria, workforce is determined in relation to the categories according to a preferable pyramid, while staff composition is economically feasible and the required service level is reached.

These three evaluation criteria are in the present paper translated into a MILP model. Different types of tasks developed by workforce are considered for optimisation purposes. The teaching requirements can be deduced from quantifiable and historic data published by the university. Management duties assigned to workforce are also addressed and quantified from data published by the university. The remaining tasks, research and technology transfer are taken into account in an indirect way, by considering a preferable staff composition. Uniquely addressing teaching tasks, the optimisation problem could conclude with a workforce composition in which all workers are comprised within the categories with best performance (greatest teaching capacity/salary ratio). However, it is important to include other categories that, even not offering the best economic performance in teaching, are fundamental for research and technology transfer. For instance, a university may intensify efforts in research and technology transfer by adopting a workforce composition with an important share in PhD students and assistant professors. This, for sure, does not mean that experienced professors under permanent categories do not contribute in such activities (in fact they usually do research), but $\mathrm{PhD}$ students and assistant professors are supposed to focus intensively on them. In addition, such composition will also ensure the continuity of future permanent experienced categories retaining the generated knowledge in the organisation. So, modulating the size of workforce held by $\mathrm{PhD}$ students and experienced professors one can also modulate the volume of research and technology transfer carried out in the university.

The strategic decisions that mostly affect the workforce are:

1 personnel policies (e.g., staff budget, promotions and types on contracts), because on them depend the permanence and the expertise career of the workers (Section 4.2.1)

2 those related to academic policies that influence the demand of teaching hours (for example, creating or eliminating courses or studies, assigning students to small or big groups...), as the number of workers is dimensioned according to these requirements (Section 4.2.2).

Finally, we consider important to establish a preferable university model (in composition and size) to ensure the service quality and the continuity of the educational model (Section 4.2.3). These three aspects (academic policies, personnel policies and preferable composition) have effect in the setting up process of the strategic capacity plan of the university (this is graphically explained in Figure 1). Therefore, they are the principal objects of study, specifically addressed in the present paper. Instead, de la Torre et al. (2016) only considers the link between model and workforce composition. The following sections of the paper deal with the model formulation, the solving and the discussion for a numerical example using real data. 
Figure 1 Summary of the scope of the article (see online version for colours)

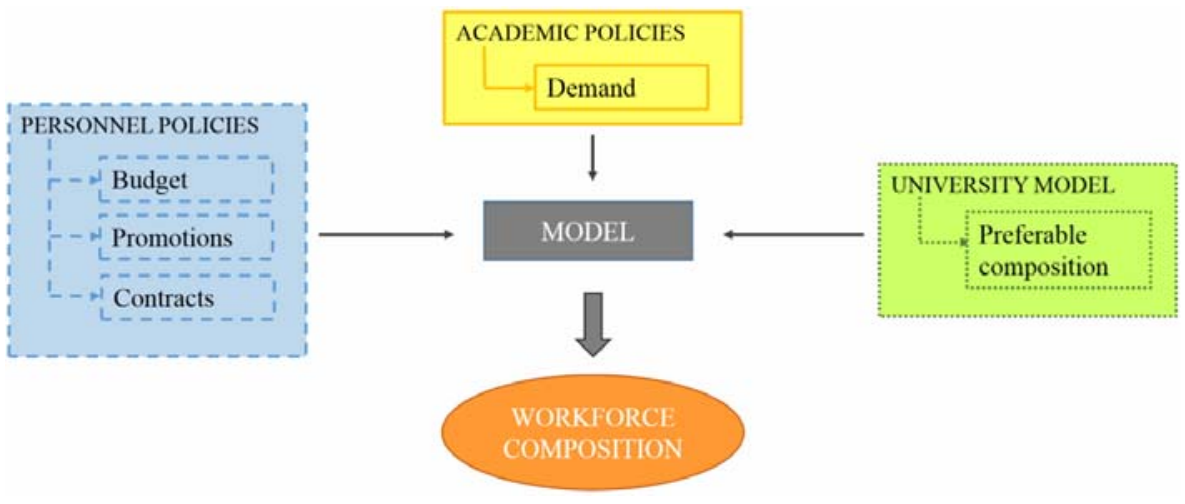

\section{Model formulation}

The problem has been modelled by using a MILP, which is based on the model proposed by de la Torre et al. (2016). The input data are presented in Table 1. Table 2 presents other input data for the problem, referred to a particular optimisation criteria. For instance, some parameters are added so as to penalise deviations between preferable and planned workforce composition. Then, variables are divided in two groups: decision variables, which are presented in Table 3, and the rest of variables, included in Table 4. The section finishes with the model formulation in which we introduce a new constraint.

Table 1 Data description

\begin{tabular}{ll}
\hline Data & Description \\
\hline$T$ & Set of periods (years) comprising the time horizon for optimisation. \\
$U$ & Set of units or university departments. \\
$K$ & Set of categories for workforce. \\
$K T$ & Subset of temporary categories for workforce. \\
$K C$ & Subset of contractual categories for workforce. \\
$K P$ & Subset of permanent categories for workforce. \\
$K_{k}^{+}$ & Set of categories to which it is possible to access from the category $k[k \epsilon K]$. \\
$K_{k}^{-}$ & Set of categories from which it is possible to access to the category $k[k \epsilon K]$. \\
$C W_{k t}$ & Cost in monetary units per worker, [mu/worker], associated to the category $k$ in the \\
& period $t[k \epsilon K, t \epsilon T]$. \\
$C D$ & Cost in monetary units [mu] associated to dismissing personnel. \\
$C A_{t}$ & Cost in [mu/hour] associated to part time lecturers in the period $t[t \epsilon T]$. \\
$C_{u t}$ & Required capacity in [hour] for the unit $u$, in the period $t[u \epsilon U, t \in T]$ \\
\hline
\end{tabular}


Table 1 Data description (continued)

\begin{tabular}{|c|c|}
\hline Data & Description \\
\hline$H_{k t}$ & $\begin{array}{l}\text { Capacity in [hour] associated to each worker in the category } k \text { in the period } \\
t[k \in K, t \in T] .\end{array}$ \\
\hline$L_{u k t}$ & $\begin{array}{l}\text { Expected personnel layoffs (for instance, due to retirement or to previously agreed } \\
\text { dismissal) in the unit } u \text {, category } k \text { and period } t[u \in U, k \in K, t \epsilon T] \text {. }\end{array}$ \\
\hline$R_{\text {uskt }}$ & $\begin{array}{l}\text { Proportion of workers in the unit } u \text { that can promote, as maximum, from the } \\
\text { category } s \text { to the category } k \text {, in the period } t[u \in U, s \in S, k \in K, t \in T] \text {. }\end{array}$ \\
\hline$B_{t}$ & $\begin{array}{l}\text { Planned budget in monetary units }[\mathrm{mu}] \text { for the salaries of the workforce in the period } \\
t[t \in T] .\end{array}$ \\
\hline$E C_{u t}$ & $\begin{array}{l}\text { Excess of capacity that should have, at least, the unit } u \text { in the period } \\
t[u \epsilon U, t \in T] . \text { Even if it is not usual, this parameter could be negative if a shortage in } \\
\text { the capacity is allowed; this would mean a worsening in the service level (for } \\
\text { example, a high number of students in a teaching room). }\end{array}$ \\
\hline$M D$ & Maximum bound for the number of workers that can be dismissed. \\
\hline Table 2 & Additional data \\
\hline Parameter & Description \\
\hline$\psi_{k t}^{+}, \psi_{k t}^{-}$ & $\begin{array}{l}\text { Preferable bounds for the proportion of the workforce that belongs to the category } \\
k \text { in the period } t[k \epsilon K, t \in T] \text {. This condition is not hard, but non-compliance is } \\
\text { penalised. }\end{array}$ \\
\hline$\lambda_{k t}$ & $\begin{array}{l}\text { Penalty associated to the discrepancy between the preferable and the planned } \\
\text { composition of the workforce in the category } k \text { and period } t[k \in K, t \in T] .\end{array}$ \\
\hline$\mu_{t}$ & $\begin{array}{l}\text { Penalty in monetary units }[\mathrm{mu}] \text { associated to the maximum discrepancy between } \\
\text { the preferable and the planned composition of the workforce in the period } t[t \in T] \text {. }\end{array}$ \\
\hline$\omega$ & $\begin{array}{l}\text { Penalty in monetary units }[\mathrm{mu}] \text { associated to the maximum discrepancy between } \\
\text { the preferable and the planned composition of the workforce. }\end{array}$ \\
\hline Table 3 & Decision variables \\
\hline Variable & Description \\
\hline$w_{u k t} \in \mathbb{Z}^{+}$ & Number of workers of the unit $u$, category $k$ and period $t[u \epsilon U, k \in K, t \in T]$ \\
\hline$a_{u t} \in \mathbb{R}^{+}$ & $\begin{array}{l}\text { Capacity in [hour] assigned to part time lecturers in the unit } u \text { and period } \\
t[u \in U, t \in T]\end{array}$ \\
\hline$q_{u s k t} \in \mathbb{Z}^{+}$ & $\begin{array}{l}\text { Number of workers who access to the category } k \text { from the category } s \text {, in the } \\
\text { unit } u \text { and period } t[u \epsilon U, s \in S, k \in K, t \in T] \text {. }\end{array}$ \\
\hline$w_{u k t}^{+} \in \mathbb{Z}^{+}$ & $\begin{array}{l}\text { Number of workers who are hired from the labour market for the unit } u \text { and } \\
\text { category } k \text {, in the period } t[u \epsilon U, k \in K, t \in T] \text {. }\end{array}$ \\
\hline$w_{\text {ukt }}^{-} \in \mathbb{Z}^{+}$ & $\begin{array}{l}\text { Number of dismissed workers (excluding retirements) in the unit } u \text { and the } \\
\text { category } k \text {, in the period } t[u \epsilon U, k \in K, t \in T] \text {. }\end{array}$ \\
\hline
\end{tabular}


Table $4 \quad$ Other variables

\begin{tabular}{ll}
\hline Variable & Description \\
\hline$d_{u k t}^{+}, d_{u k t}^{-} \in \mathbb{R}^{+}$ & $\begin{array}{l}\text { Positive and negative discrepancies, respectively, between the preferable and } \\
\text { the planned composition of the workforce in the unit } u \text {, category } k \text { and period } \\
t[u \in U, k \in K, t \in T] .\end{array}$ \\
$d_{u t} \in \mathbb{R}^{+}$ & $\begin{array}{l}\text { Maximum discrepancy (positive or negative), between the preferable and the } \\
\text { planned composition of the workforce in the unit } u \text { and all the categories in } \\
\text { the period } t\left(\text { i.e., } d_{u t}=\max _{k}\left(d_{u k t}^{+}, d_{u k t}^{-}\right)\right)[u \epsilon U, t \in T] .\end{array}$ \\
& $\begin{array}{l}\text { Maximum discrepancy between the preferable and the planned composition } \\
\text { of workforce }\left(d_{t}=\max _{t}\left(d_{u t}\right)\right) .\end{array}$ \\
\hline
\end{tabular}

- Model

$$
\begin{aligned}
{[M I N] z } & =\sum_{u \in U, t \in T}\left[\sum_{k \in K}\left(C W_{k t} \cdot w_{u k t}\right)+C A_{t} \cdot a_{u t}\right]+C D \cdot \sum_{u \in U, k \in K C, t \in T} w_{u k t}^{-} \\
& +\sum_{u \in U, k \in K, t \in T}\left[\lambda_{k t} \cdot\left(d_{u k t}^{+}+d_{u k t}^{-}\right)\right]+\sum_{u \in U, t \in T}\left(\mu_{t} \cdot d_{u t}\right)+\omega \cdot \sum_{t \in T} d_{t}
\end{aligned}
$$

Subject to

$$
\begin{aligned}
& \sum_{k \in K} w_{u k t} \cdot H_{k t}+a_{u t} \geq\left(1+E C_{u t}\right) \cdot C_{u t} \quad u \epsilon U, t \epsilon T \\
& w_{u k t}=w_{u k t-1}-L_{u k t}+\sum_{s \in K_{\bar{k}}} q_{u s k t}-\sum_{k \epsilon K_{k}^{+}} q_{u s k t}+w_{u k t}^{+}-w_{u k t}^{-} \quad u \epsilon U, k \epsilon(K C \cup K P), t \epsilon T \\
& w_{u k t}=\sum_{s \in K_{\bar{k}}} q_{u s k t}+w_{u k t}^{-} \quad u \in U, k \in K T, t \in T \\
& q_{u s k t} \leq R_{u s k t} \cdot w_{u k, t-1} \quad u \in U, s \in K \mid K_{s}^{+} \neq\{\varnothing\}, \\
& w_{u k t} \geq\left(\psi_{k t}^{-} \cdot \sum_{k \in K} w_{u k t}\right)-d_{u k t}^{-} \quad u \epsilon U, k \epsilon K, t \epsilon T \\
& w_{u k t} \leq\left(\psi_{k t}^{+} \cdot \sum_{k \in K} w_{u k t}\right)+d_{u k t}^{+} \quad u \epsilon U, k \epsilon K, t \epsilon T \\
& d_{u t} \geq d_{u k t}^{+}+d_{u k t}^{-} \quad u \epsilon U, k \epsilon K, t \epsilon T \\
& d_{t} \geq d_{u t} \quad u \in U, t \in T \\
& w_{u k t}^{-} \leq M D \cdot w_{u k t}+1 \quad u \in U, k \in K C, t \in T \\
& \sum_{u \in U}\left[\sum_{k \in K}\left(C W_{k t} \cdot w_{u k t}\right)+C A_{t} \cdot a_{u t}\right] \leq B_{t} \quad t \in T \\
& w_{u k t}, a_{u t}, q_{u s k t}, w_{u k t}^{+}, w_{u k t}^{-}, d_{u k t}^{-}, d_{u k t}^{+}, d_{u t}, d_{t} \geq 0 \quad u \in U, k \in K, t \in T
\end{aligned}
$$


Equation (1) presents the objective function. The aim is to minimise the costs associated to:

1 the salaries of the workers per each category $k$, unit $u$ and time

$$
t\left(\sum_{u \in U, t \in T}\left[\sum_{k \in K}\left(C W_{k t} \cdot w_{u k t}\right)+C A_{t} \cdot a_{u t}\right]\right)
$$

2 penalties for dismissals $\left(C D \cdot \sum_{u \in U, k \in K, t \in T}\left(w_{u k t}^{-}\right)\right)$

3 those costs associated to discrepancies between the preferable and the planned composition in the workforce

$$
\left(\sum_{u \in U, k \in K, t \in T}\left[\lambda_{k t} \cdot\left(d_{u k t}^{+}+d_{u k t}^{-}\right)\right]+\sum_{u \in U, k \in K} \mu_{t} \cdot d_{u t}+\omega \cdot \sum_{t \in T} d_{t}\right)
$$

Equation (2) determines the minimum available capacity considering the service level. Equations (3) and (3') balance the number of the staff members for each category, unit and period. As frequently, there is a limitation on the spots, an upper bound on the number of workers to be promoted is imposed in (4). Constraints regarding the preferable composition of the workforce (between an upper and a lower bound) are included in equations (5) and (6). Constraints (7) and (8) permit to calculate the maximum discrepancies within all categories and periods, to avoid, insofar as possible, that the discrepancy is concentrated in few categories or periods (is a regular distribution of the discrepancy preferable). Constraint (9), not used in de la Torre et al. (2016), limits the number of workers dismissed in categories within subset $K C$, and for all units and periods. Constraint (10) takes into account the budget for salaries of the workforce per period. Finally, constraint (11) imposes that the variables are non-negative.

There are universities that prioritise promotions over foreign contracting, aiming to return the investment in personnel training. In order to represent these policies in the model, a binary variable $y_{u s k t}$ is defined. This is an auxiliary variable for modelling the condition of prioritising the promotion of the current workers from the category $s$ to the category $k$ over hiring workers from the labour market, in the unit $u$, category $k$, and period $t$. Therefore, constraints (12) to (14) should be added to the above model:

$$
\begin{array}{ll}
y_{u s k t} \in\{0,1\} & u \in U, s \in K \mid K_{s}^{+} \neq\{\varnothing\}, k \in K_{s}^{t}, t \in T \\
q_{u s k t} \geq R_{u s k t} \cdot w_{u k, t-1}-R_{u s k t} \cdot\left(\frac{C_{u t} \cdot\left(1+E C_{u t}\right)}{H_{k t}}\right) & u \epsilon U, s \in K \mid K_{s}^{+} \neq\{\varnothing\}, k \in K_{s}^{t}, t \in T \\
\cdot y_{u s k t}-1 & u \in U, s \in K \mid K_{s}^{+} \neq\{\varnothing\}, k \in K_{s}^{t}, t \in T \\
w_{u k t}^{+} \leq\left(\frac{C_{u t} \cdot\left(1+E C_{u t}\right)}{H_{k t}}\right) \cdot\left(1-y_{u s k t}\right) &
\end{array}
$$

Equations (13) and (14) force $w_{u k t}^{+}$equal to zero provided that the number of workers promoted to a category $k$ does not exceed the upper bound defined by the expression $\left(C_{u t} \cdot\left(1+E C_{u t}\right) / H_{k t}\right)$. 


\section{Numerical example}

This section introduces a numerical example for analysis and in this regard, the contents in this section are twofold. First, data and specificities for a public university in Spain, the Universitat Politècnica de Catalunya (UPC, 2014) are introduced. Second, contents present the scenarios for analysing the effect that academic and personnel policies as well as the preferable workforce composition criteria, have in the determination of the strategic staff plan. All these contents serve as a basis for results discussion in Section 5 . The analyses are made on the same example as in de la Torre et al. (2016).

\subsection{Description of the UPC case}

The UPC created in 1971 is one of the top ten universities in Spain; the portfolio of this public university holds 68 degrees and masters, mainly in the field of engineering, altogether hosting more than 30,000 students in 23 schools and faculties. At the start time of this work, the total workforce (academic and non-academic personnel) exceeds 3,000 people distributed in 42 units $(u=42)$ or departments. The academic workforce, considered for optimisation purposes in the present paper, reaches 1999 people.

There are two main types of categories for academic workforce: temporary and permanent ones.

Workers in training periods are the main staff for temporary categories $K T$; so, their capacity is lower than that for workers within permanent categories. Their work contracts are annually renewed and they are supposed to progress to a higher category once a certain period of time is exhausted; otherwise, they lose their job position.

Regarding permanent categories, workers can follow two different career pathways: contractual and public/tenure ones. The main difference between them, for strategic decisions, is that only workers following the contractual pathway $K C$ can be dismissed, provided economic compensation though. On the other hand, promotion in the tenure pathway $K P$ is harder than in the contractual one, because the availability of new spots is fewer. Further, it is convenient to note that, although non-conventional, workers can switch between the contractual and public pathways by horizontal or vertical promotion. The total number of categories for the UPC is 15 . The first eight categories comprise the subset $K T$, thus leaving seven permanent categories. Amongst them, three correspond to the subset $K C$ and 4 are within the subset $K P$.

The model requires several data: economic costs, regulations, promotions and retirements, among other factors (see Section 2). The sources for such information are listed in the following:

- $\quad$ Personnel capacity $H_{k t}$ and costs $\left(C W_{k t}, C A_{t}\right)$ are public information (UPC, 2014) and these will be considered constant throughout the time horizon for analysis.

- The required capacity (demand) for each unit or department is deduced from the number of students for the subjects given by each department of the university, and also from the credits assigned to each of the subjects (UPC, 2014). The demand can be modified in some computational scenarios (see Section 5.3) for addressing the impact of different academic policies in the determination of the strategic staff plan. 
- $\quad$ The expected personnel retirements $L_{k t}$ and internal promotions $R_{u s k t}$ are computed from historical data (ANECA, 2014; AQU, 2014; Ministry - Ministerio de Educación, Cultura y Deporte, 2014). This is as well for estimating the minimum required excess of capacity for each category $E C_{u}$, which is accepted around $15 \%$, according to UPC (2014). This capacity oversizing is due to the reduction in the effective workers' capacity for addressing management tasks.

- $\quad$ The sets of categories $K_{k}^{+}$and $K_{k}^{-}$derive from the regulatory framework applied to public universities (ANECA, 2014; AQU, 2014; Ministry - Ministerio de Educación, Cultura y Deporte, 2014). Dismissals for workers within $K C$ are also bounded by regulations. In the model, this is regulated by the parameter $M D$.

- The budget $B_{t}$ for the university is estimated from public information in the website of the university (UPC, 2014).

- An eight-year horizon is considered adequate for the strategic capacity planning, since it comprises two full legislatures of the rector and university government team.

Apart from the input data indicated above, and with the aim of achieving a preferable workforce composition, the mathematical optimisation model requires to define further parameters, which are listed below:

- Bounds $\psi_{k t}^{+}$and $\psi_{k t}^{-}$for the proportion of each category in the workforce are assumed with a relative deviation of up to $35 \%$ from the defined preferable composition. For instance, given a preferable composition of $10 \%$ of total workforce for a category $k$ and period $t$, the planned workforce composition without incurring in penalisation results within the interval $10 \% \pm 10 \bullet 0.35$, so between $(6.5 \% ; 13.5 \%)$. These bounds have been selected to guarantee the achievement of feasible solutions.

- In case of discrepancy between the preferable and the planned composition, the economic penalty $\lambda_{k t}$ has been set as the annual salary per each category and worker. Also, penalty $\mu_{t}$ is calculated as a proportion [around $5 \%$ based on historical data (UPC, 2014)] of the annual average budget per department. Further, the penalty $\omega$, as associated to the maximum discrepancy between the preferable and the planned workforce, is assumed as a proportion of the annual budget for the entire university [around 1\%, based on historical data (UPC, 2014)].

\subsection{Description of scenarios}

This section proposes several scenarios for analysing the effect that different strategic policies (such as those related to personnel, academic-type and the adopted university model) can have in the definition of the long-term staff plan.

\subsubsection{Personnel policies}

The aim of personnel policies is to support and enable the construction of a university model and according to the regulatory framework. In regard of personnel policies, the present paper proposes two different types of analyses for discussion. The first type is related to contract policies addressing the impact of permitting or not dismissing workers in permanent categories within the subset $K C$. In some universities, workers within these 
categories can be dismissed and this is the main difference with workers under $K P$. Also, this first type of analyses refers to the discussion of favouring the internal promotions against hiring new workers from the labour market. By favouring the internal promotions, the university would express the intention of amortising the money spent in training workers while in their first years of career. Note that in practice, prioritising promotions over foreign contracting means to activate model constraints (12) to (14).

The second type of analyses addresses the impact of considering different admissible promotional ratios and personnel budget. The achievement of a preferable workforce composition and economic optimisation may be challenged by constraining personnel promotions and economic resources, and this is going to be addressed in this analysis. In practice, this implies to vary over the time the model input data: the personnel budget $B_{t}$ and the promotion ratio $R_{u s k t}$. In particular, $R_{u s k t}$ and $B_{t}$ have been considered constant, monotonically increasing or decreasing at different ratios throughout the considered time horizon (eight years). This yields different scenarios for analysis.

\subsubsection{Academic policies}

Academic policies refer, amongst other factors, to the determination of the number, location and type of degrees that students can apply to, as well as to the design of the academic programs (number of years, subjects, etc.). All these factors greatly affect the demand (the number of students willing to be enrolled in the university). The requirements are also influenced by the educational model; for example, a small number of students per group increases the number of required lecturers for teaching purposes. The analyses aim to evaluate the impact that different trends in demand have in the strategic staff plan. In practice, demand $C_{u t}$ has been considered constant, monotonically decreased and increased by $1.5 \%$ per year.

\subsubsection{University model}

Bearing in mind different strategic visions one can come up with different preferable workforce structures for universities. These strategic visions refer to several factors, such as the generational replacement, personnel training, experience and capacity of workers, as well as others related to the vocation of the university to develop different kind of activities such as transfer of technology. In order to establish the preferable compositions, a poll on university management was addressed to a selected group of relevant academics. The results of the poll yielded three preferable compositions:

- Model A: The university is devoted to create knowledge that should be exported to other sectors. In this regard, one can define an academic structure based on the training of a huge volume of assistant professors and $\mathrm{PhD}$ students that cannot only provide enough people to build up future generations of permanent categories, but they also feed other universities and industry. This yields a workforce composition with an important share in personnel within $K T$. This subset presents high rotation rates and a reduced capacity; so, this envisages a workforce with higher number of workers and personnel hired from labour market than in other models. 
- Model B: Attending to the generational replacement, it is necessary to develop mentoring programs for PhD students and assistant professors. These programs will favour the sustainability of the organisation, ensuring a proper volume of workers to build up future permanent categories. Therefore, the university can retain the generated knowledge. As a difference with model A, the aim of adopting this model is not to export knowledge to other sectors of society. So, the desired percentage of total workers in $K T$ is sensibly lower than in model A.

- Model C: By decreasing the share of workers in $K T$, this model $\mathrm{C}$ proposes to configure a university workforce with high knowledge expertise. This vision could be adopted bearing in mind that experienced workforce can develop more tasks and with better performance than those carried out by less experienced workers. One potential drawback of this model is the advisable scarcity of young researchers in $K T$. Therefore, the generational replacement could be compromised and/or satisfied by just hiring workers from labour market.

The numerical results of the above-mentioned poll yielding all three university models are summarised in Table 5. The last column corresponds to the real situation in the UPC at the end of 2014. As it can be noted, for all university models, the desired share in categories within $K C$ is almost the same. This is because usually workers that access to these categories aim to gain a position in $K P$.

Given the contract policies for the UPC in the last years, the current workforce structure is closer to model $\mathrm{C}$ than to the rest. It is remarkable the little amount of workers in $K T$ (just $18 \%$ of total workers); thus, permanent contracts for experienced workers with high capacity are preferred.

Table 5 Proposed university models and current UPC structure

\begin{tabular}{|c|c|c|c|c|c|}
\hline \multicolumn{2}{|c|}{ 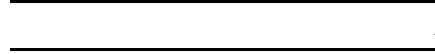 } & Model A & Model B & Model C & UPC structure \\
\hline \multicolumn{2}{|c|}{ Proportion of workers in $K T$} & $42 \%$ & $34 \%$ & $27 \%$ & $18 \%$ \\
\hline \multicolumn{2}{|c|}{ Proportion of workers in $K C$} & $17 \%$ & $18 \%$ & $16 \%$ & $20 \%$ \\
\hline \multicolumn{2}{|c|}{ Proportion of workers in $K P$} & $41 \%$ & $48 \%$ & $57 \%$ & $62 \%$ \\
\hline \multicolumn{6}{|c|}{ Table 6 Scenarios for analysis } \\
\hline Issues & Demand & $\begin{array}{l}\text { Promotional } \\
\text { ratio and } \\
\text { personnel } \\
\text { budget } \\
\end{array}$ & $\begin{array}{l}\text { Dismissals } \\
\quad \text { in } K C\end{array}$ & $\begin{array}{l}\text { Priority to } \\
\text { internal } \\
\text { promotions }\end{array}$ & $\begin{array}{c}\text { Scenario per } \\
\text { university } \\
\text { model }\end{array}$ \\
\hline \multirow{3}{*}{$\begin{array}{l}\text { Dismissals and } \\
\text { internal promotions } \\
\text { (Section 5.1) }\end{array}$} & Constant & Constant & Yes & No & $1 \mathrm{~A}, 1 \mathrm{~B}, 1 \mathrm{C}$ \\
\hline & Constant & Constant & No & No & $2 \mathrm{~A}, 2 \mathrm{~B}, 2 \mathrm{C}$ \\
\hline & Constant & Constant & No & Yes & $3 \mathrm{~A}, 3 \mathrm{~B}, 3 \mathrm{C}$ \\
\hline \multirow{3}{*}{$\begin{array}{l}\text { Promotions and } \\
\text { personnel budget } \\
\text { (Section 5.2) }\end{array}$} & Constant & Increasing & Yes & No & $4 \mathrm{~A}, 4 \mathrm{~B}, 4 \mathrm{C}$ \\
\hline & Constant & Decreasing & Yes & No & $5 \mathrm{~A}, 5 \mathrm{~B}, 5 \mathrm{C}$ \\
\hline & Constant & Decreasing & No & Yes & $6 \mathrm{~A}, 6 \mathrm{~B}, 6 \mathrm{C}$ \\
\hline \multirow{2}{*}{$\begin{array}{l}\text { Demand } \\
\text { (Section 5.3) }\end{array}$} & Increasing & Constant & No & Yes & $7 \mathrm{~A}, 7 \mathrm{~B}, 7 \mathrm{C}$ \\
\hline & Decreasing & Constant & No & Yes & $8 \mathrm{~A}, 8 \mathrm{~B}, 8 \mathrm{C}$ \\
\hline
\end{tabular}




\subsubsection{Summary of the proposed scenarios for study}

All the proposed issues discussed in Sections 4.2.1 to 4.2.3 are translated into 24 different scenarios for optimisation, which are summarised in Table 6 for the sake of clarity. The model has been executed ten times for each scenario varying the parameters $\psi_{k t}^{+}$and $\psi_{k t}^{-}$ (the preferable bounds for the proportion of workers that belong to the category $k$ in the period $t$ ). Their respective results are discussed in Sections 5.1 to 5.3.

\section{Analysis of the results}

The following sections present the computational results obtained from solving the scenarios summarised in Table 6 . With the aim of evaluating the performance, different metrics are used. Some of them are defined in de la Torre et al. (2016).

The first one, metric $R C_{u k t}$, is the proportion of the members in a category $k$ over the whole staff of the unit $u$ at the period $t$. Therefore, $0 \leq R C_{u k t} \leq 1$.

$$
R C_{u k t}=\frac{w_{u k t}}{\sum_{k \epsilon K} w_{u k t}} \quad u \epsilon U, k \epsilon K, t \epsilon T
$$

Now, $P C_{k}$ is the preferable percentage of category $k$ in the university workforce composition (expressed in per unit). From $P C_{k}$ and the above defined staff proportion $R C_{u k t}$, a new metric can be set, named here as global discrepancy $G D_{u t}$, which is computed as:

$$
G D_{u t}=\sum_{k \in K}\left|P C_{k}-R C_{u k t}\right| \quad u \epsilon U, t \epsilon T
$$

This metric provides, per each unit $u$ and period $t$, the discrepancy between preferable and obtained workforce compositions. Note that since it accumulates the discrepancy associated to each category, the obtained value can exceed 1: $0 \leq G D_{u t} \leq|K|$.

With a higher level of aggregation, the global discrepancy $G D_{u t}$ can be averaged for all units or departments of the university. This leads to a third metric defined for each period $t$, the average global discrepancy, $\overline{G D}_{t}$, which is computed as:

$$
\overline{G D}_{t}=\frac{\sum_{u \epsilon U} G D_{u t}}{|U|} \quad t \in T
$$

Finally, the last metric $Z_{t}$ computes the cost for each period $t$ related to personnel management, i.e., salaries and costs associated to dismissals. This metric is defined as:

$$
Z_{t}=\sum_{u \in U}\left[\sum_{k \in K}\left(C W_{k t} \cdot w_{u k t}+C D \cdot w_{u k t}^{-}\right)+C A_{t} \cdot a_{u t}\right] \quad t \in T
$$

\subsection{Discussion on the impact of personnel policies concerning contracts}

The following discussion explores in what ways the possibility of dismissing personnel within $K C$ affects the optimisation of the staff plan for the university. Moreover, discussion goes around the impact of prioritising inside promotions against hiring new 
workers from the labour market. To this aim, the data used correspond to the first three computational scenarios and for each of the three university models under consideration A, B and C (see Table 6).

As noted in Table 6, a constant demand, workforce promotion ratio and personnel budget over the considered horizon are considered constant for the three computation scenarios. They differ in the applied contractual personnel policies. In the first one, dismissals for workers within $K C$ are permitted, but there is no policy favouring the promotion of the workers of the university over those from the labour market. Conversely, in the second scenario, dismissals for workers belonging to $K C$ are not permitted and as in the first scenario, there is no policy favouring the internal promotion. Finally, in the third scenario, dismissals for workers belonging to $K C$ are not permitted, but as a difference with the second scenario, workers already working at the university are prioritised over the rest. These three scenarios permit to evaluate the impact of these personnel policies, without the influence of other aspects.

\subsubsection{Discussion on dismissals for personnel in}

The results for the first and second scenarios show that the possibility of dismissing workers within $K C$ has very little influence in the achievement of a preferable workforce composition under the considered time horizon and for all the university models. This can be graphically observed in Figure 2, which plots the average global discrepancy, $\overline{G D}_{t}$.

As it can be noted in Figure 2, major changes in workforce composition are applied in the very first years. These changes mainly correspond to the decision of promoting and/or dismissing workers within $K C$ to other categories within $K C$ or $K P$. The adjustment of the workforce composition to the preferable one is quite slow in the subsequent years. This is due to the resiliencies against changes in permanent categories within $K P$. Workers in these categories cannot be dismissed and are already at the top of the workforce pyramid. So, their promotion ratio to other categories is low and the size of these categories is mainly reduced through retirements.

Further, it is interesting to note the difference in the trend for the model $\mathrm{A}$ in comparison to those for the models B and C. This is because, as indicated in Table 5, the initial composition of the university is very different from the model A, especially for categories in $K T$ and $K P$. The need of reducing the weight of $K P$ in workforce takes more time than modulating the composition of $K T$ and $K C$, since workers in $K P$ normally leave the organisation just in case of retirement. Thus, such restriction for modulating the workforce in $K P$ affects the achievement of the preferable composition.

The effect of having the possibility of dismissing or not workers in $K C$ can be further analysed in Table 7. Table 7 presents the decision variables $q_{u s k}$ (number of workers belonging to the unit $u$ who access to the category $k$ from the category $s$ at time $t$ ), for all the categories and only in $K C, w_{u k t}^{-}$(number of workers fired at time $t$, in the unit $u$, category $k$ ) and $w_{u k t}$ for scenarios 1 and 2 . As it can be noted, there is a great number of movements of workers (see variable $q_{u s k t}$ ) in the university along the horizon. At the end, though, the total number of workers for both scenarios is almost the same $(1,599$ compared to 1,597 for the model A, 1,533 compared to 1,512 for the model B and 1,443 compared to 1,430 for the model C). This denotes that, despite dismissing workers within $K C$ is not possible, the model successes in determining almost the same workforce. However, such workforce is achieved differently for scenarios 1 and 2. For scenario 1 , 
between $17 \%$ to $22 \%$ of total movements correspond to workers in categories within $K C$ (164 out 921 total movements for the model A, 189 out 849 total movements for the model $\mathrm{B}$ and 132 out 672 total movements for the model C). The percentage of movements for workers in $K C$ is higher in scenario 2, i.e., in the case dismissing workers in $K C$ is forbidden, along with an increment in total movements for all university models. It can be seen that approximately all workers dismissed in scenario 1 (129 workers for the model A, 132 for the model B and 160 for the model C) are promoted in scenario 2 (the sum of the 129 workers fired in scenario 1 plus the 164 promoted workers in $K C$ approximately corresponds to the total number of workers promoted in scenario 2, 293 out 311$)$.

Figure 2 Average global discrepancy for models A, B and C, in scenarios 1 and 2 for the evaluation of personnel contractual policies (see online version for colours)

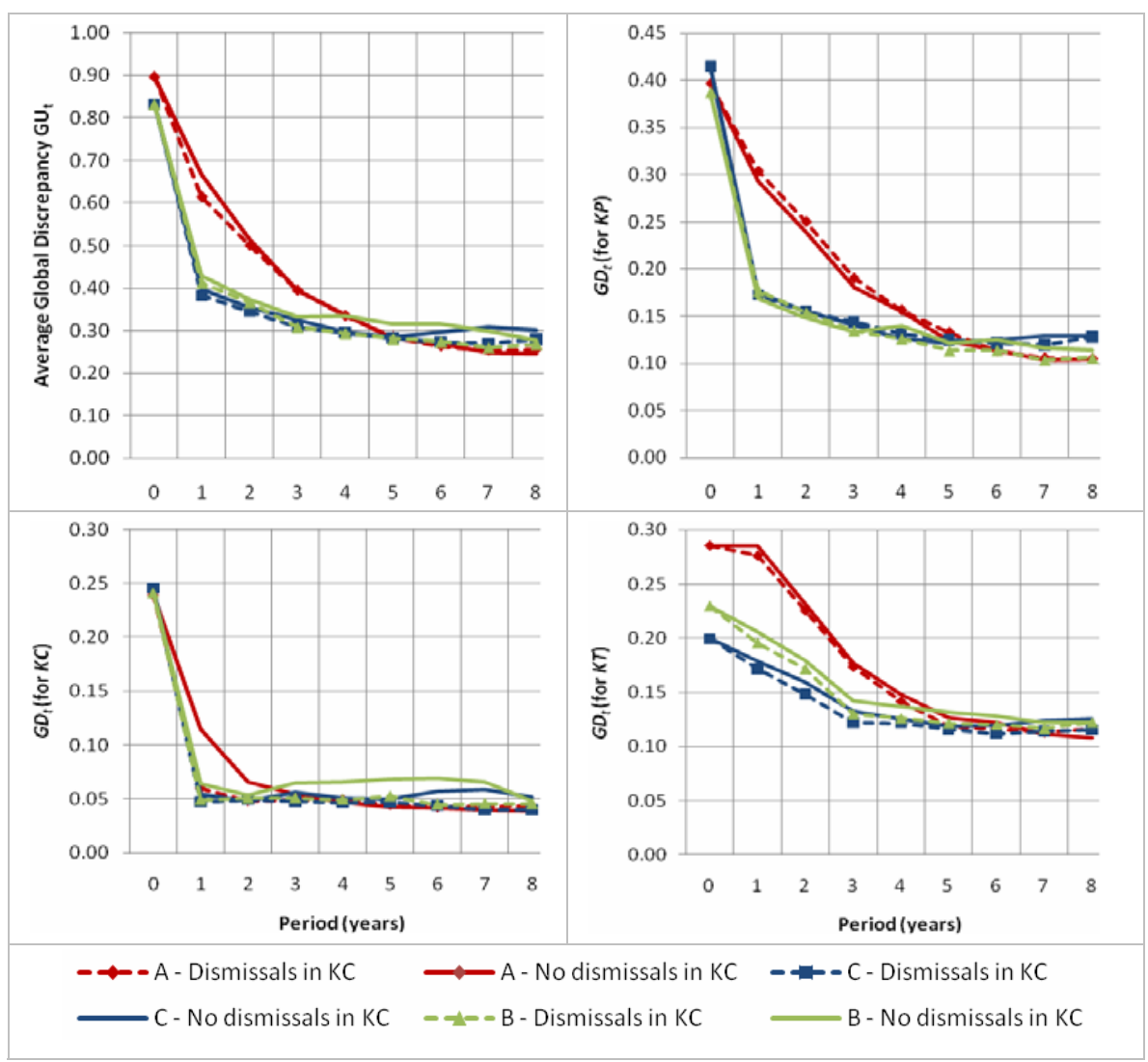


Table 7 Assessment of promotions and dismissed personnel (during the time horizon) and final workforce size for models A, B and C in scenarios 1 and 2

\begin{tabular}{|c|c|c|c|c|c|c|}
\hline \multirow[t]{2}{*}{ Variable } & \multicolumn{3}{|c|}{$\begin{array}{c}\text { Scenario } 1 \text { (dismissals in } K C \\
\text { permitted) }\end{array}$} & \multicolumn{3}{|c|}{$\begin{array}{c}\text { Scenario } 2 \text { (dismissals in } K C \\
\text { not permitted) }\end{array}$} \\
\hline & Model A & Model B & Model C & Model $A$ & Model B & Model C \\
\hline$\sum_{u \in U, s \in K, k \in K, t \in T}^{\text {Movements: }} q_{u s k t}$ & 921 & 849 & 672 & 1,039 & 961 & 841 \\
\hline $\begin{array}{l}\text { Promotions in } K C: \\
\sum_{u \in U, s \in S, k \in K, t \in T} q_{u s k t}\end{array}$ & 164 & 189 & 132 & 311 & 309 & 314 \\
\hline$\sum_{u \in U, k \in K, t \in T}^{\text {Dismissals: }} w_{u k t}^{-}$ & 129 & 132 & 160 & 0 & 0 & 0 \\
\hline Workforce size at the end: & 1,599 & 1,533 & 1,443 & 1,597 & 1,512 & 1,430 \\
\hline
\end{tabular}

At this point of the analysis, it must be underlined that the total number of workers determined by the model at the end of the horizon, 1599, is much lower than 1999 (the initial workforce). Computing the ratio between the initial workforce capacity (at time 0 ) and the demand, it results an excess of capacity around $32 \%$. We should keep in mind that in order of considering management tasks for workers, a minimum workforce oversizing of about $15 \%$ should be fulfilled (see Section 4.1). Taking this into account, the 'effective' excess of workforce capacity for the UPC at the beginning of the horizon is around $17 \%$. Conversely, the excess of capacity computed at the end of the horizon results diminished from $32 \%$ to $16 \%$ approximately for all considered university models, thus becoming closer to the aforementioned $15 \%$. The results presented in all sections of this paper refer to the particular example of a university that needs a reduction in the workforce.

\subsubsection{Discussion around the priority on internal promotions}

To evaluate the impact of prioritising internal promotions over hiring workers from the labour market, scenarios 2 and 3 are compared (see Table 6 ). The obtained computational results are summarised in Table 8 .

As it can be seen, the number of internal promotions is much larger in scenario 3 than in scenario 2. It results in a reduction in the number of new workers hired from the labour market (e.g., 1958 external hiring for model A in scenario 3 out of 2,306 hiring for model A in scenario 2). The final composition of the university workforce (indicated by the final number of workers) and the reduction achieved in Average Global Discrepancy are almost the same for both scenarios. The last row in Table 8 presents the total personnel management cost, according to the definition of metric $Z_{t}$ [see equation (18)]. It is interesting to note that by prioritising internal promotions, i.e., investing in personnel training, the university does not incur in larger costs related to personnel management (note the marginal cost difference between scenarios 2 and 3 in Table 8). 
Table 8 Impact assessment of internal promotions prioritised for models A, B and C, in scenarios 2 and 3

\begin{tabular}{|c|c|c|c|c|c|c|}
\hline \multirow[t]{2}{*}{ Variable } & \multicolumn{3}{|c|}{$\begin{array}{c}\text { Scenario } 2 \text { (internal promotions } \\
\text { NOT prioritised) }\end{array}$} & \multicolumn{3}{|c|}{$\begin{array}{c}\text { Scenario } 3 \text { (internal promotions } \\
\text { prioritised) }\end{array}$} \\
\hline & Model A & Model B & Model C & Model A & Model B & Model C \\
\hline $\begin{array}{l}\text { Movements: } \\
\sum_{u \in U, s \in K, k \in K, t \in T} q_{u s k t}\end{array}$ & 1,039 & 961 & 841 & 1,521 & 1,447 & 1,412 \\
\hline$\sum_{u \in U, k \in K, t \in T}^{\text {Hirings: }} w_{u k t}^{+}$ & 2,306 & 2034 & 1806 & 1,958 & 1,670 & 1,380 \\
\hline $\begin{array}{l}\text { Workforce size at the } \\
\text { end: }\end{array}$ & 1,597 & 1,512 & 1,430 & 1,594 & 1,531 & 1,436 \\
\hline$\overline{G D}_{0}-\overline{G D}_{8}$ & 0.650 & 0.553 & 0.530 & 0.644 & 0.578 & 0.531 \\
\hline$\sum_{t \in T}^{\text {Personnel costs: }} Z_{t}$ & $1,010.5 \mathrm{M} €$ & 1,001.7M€ & 986.5M€ & 1,011.1M€ & 1,003.1M€ & $990.4 \mathrm{M} €$ \\
\hline
\end{tabular}

\subsection{Discussion around the impact of personnel policies in regard of promotion ratios and personnel budget}

This section aims to evaluate the impact that different promotion ratios and personnel budget have in the determination of the strategic capacity plan. To do that, personnel budget $B_{t}$ and promotion ratio $R_{u s k t}$ have been considered monotonically increased or decreased at determined ratios throughout the considered time horizon, yielding scenarios 4 to 6 . For analysis purposes, results are compared to scenario 1 , which is characterised by concerning invariable the abovementioned factors. These analyses are discussed in the following subsections.

\subsubsection{Discussion around workers promotion ratios}

Workers promotion ratio can have great impact in the economic optimisation and in the workforce management towards a preferable composition of the university. A lower promotion ratio over the time can affect internal mobility of workers, thus forcing the university to adopt other mechanisms to be able to achieve the preferable workforce composition. In this regard, Table 9 provides a first insight on the impact of different trends in promotion ratios. Table 9 compares the results obtained from solving the proposed optimisation model for scenario 1 , in which inputs $B_{t}$ and $R_{u s k t}$ are invariable over the time, with those obtained for scenarios 4 and 5 . Scenario number 4 is characterised by the fact that the budget $B_{t}$ is monotonically increased by $1 \%$ yearly and the threshold promotion ratio $R_{u s k t}$ is, as well, monotonically increased by $5 \%$ respect to the previous year. On the other way round, scenario 5 proposes a steady decrement for the budget of $1 \%$ per year, and a decrement for $R_{u s k t}$ of $5 \%$ respect to the previous year. 
Evaluation of the impact of strategic staff planning in a university

Table 9 Impact assessment of considering different promotion ratios and personnel budget

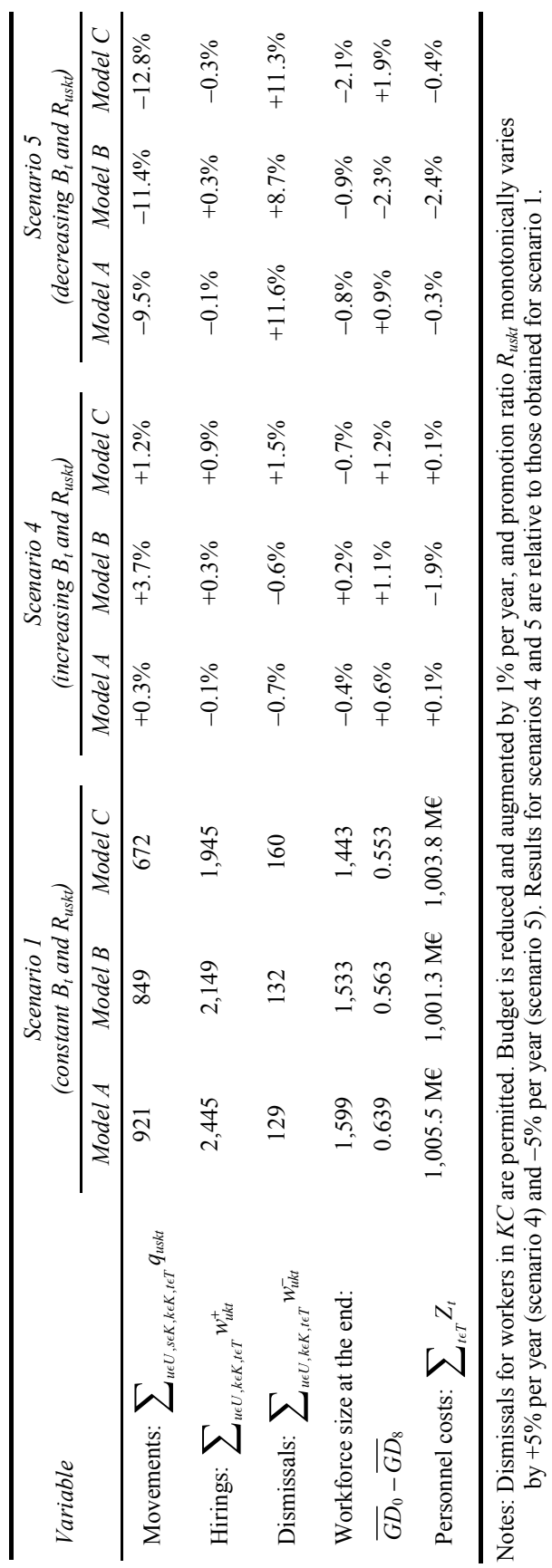


As it can be seen in Table 9, the proposed decreasing trend for promotional ratio $R_{\text {uskt }}$ in scenario 5 does have great impact in the strategic staff plan, since it greatly constrains workers promotion; the magnitude for the total decision variables $q_{u s k t}$ become reduced between $9.5 \%$ and $12.8 \%$, depending on the university model. This reduction in the number of workers promoted during the horizon is accompanied by an increment in the number of people dismissed. Thus, the possibility of dismissing workers becomes a source of flexibility towards achieving the preferable workforce composition in this case. Conversely, the impact in dismissals considering increasing $R_{u s k t}$, has low influence in Table 9 (see results for scenario 4).

\subsubsection{Discussion around personnel budget}

In the experiments carried out in Section 5.2.1, personnel budget has been considered constant, monotonically increasing or decreasing. However, this variability did not affect the obtained results because the resultant personnel costs were sensibly lower than the available budget. This can be observed in Figure 3(a), comparing the available budget for scenario 6 (university model A) with the resultant personnel costs (red line). Regardless the decreasing trends for budget, economic resources, needed to optimise the strategic staff plan were much lower than available budget. In addition, if only the economic criterion is just considered to optimise the strategic staff plan for the university (blue line), the incurred personnel costs are much lower than those obtained taking also into account the achievement of the preferable workforce composition (red line). At the end, the area comprised between the blue and the green line bounds feasible solutions for the problem.

In Figure 3(a), budget is decreased by $1 \%$ yearly, but if it is decreased in $3.5 \%$ yearly, then personnel costs for strategic staff plan optimisation can become actually constrained by the available budget, as Figure 3(b) shows. Under such scenario, the achievement of the preferable workforce composition can be compromised. This can be observed in Table 10, which presents results for university models A, B and C in scenario 6, for two different budget temporal trends. Results for the higher reduction in personnel budget are referred as relative to those obtained for small budget reductions.

Figure 3 Personnel costs and budget for scenario 6 under different budget decreasing temporal trends (see online version for colours)

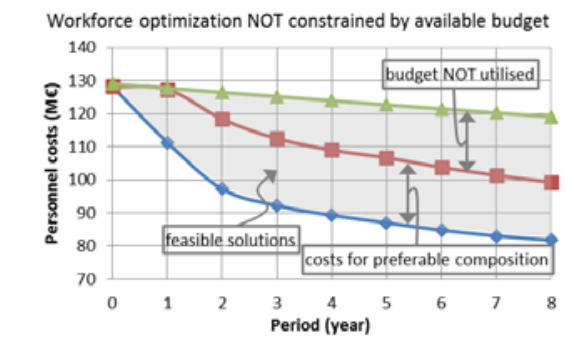

$\rightarrow$ Minimum personnel costs (without considering staff composition criteria) - - Budget $(-1 \% /$ year $)$

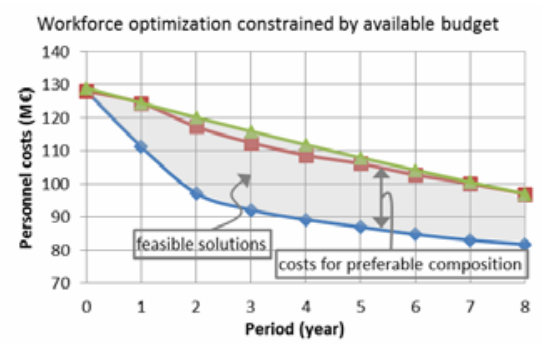

$\rightarrow$ Minimum personnel costs (without considering stat compostion criteria) - Budget $(-3.5 \% /$ vear

(a) 
Table 10 Impact assessment of considering different trends for personnel budget

\begin{tabular}{|c|c|c|c|c|c|c|}
\hline \multirow[t]{2}{*}{ Variable } & \multicolumn{3}{|c|}{$\begin{array}{l}\text { Scenario 6: small reduction for } B_{t} \\
\text { (-1\% yearly). Optimisation not } \\
\text { constrained by available budget }\end{array}$} & \multicolumn{3}{|c|}{$\begin{array}{l}\text { Scenario 6': high reduction } \\
\text { for } B_{t}(-3.5 \% \text { yearly }) . \\
\text { Optimisation constrained by } \\
\text { available budget }\end{array}$} \\
\hline & Model A & Model B & Model C & Model A & Model B & Model C \\
\hline Workforce size at the end: & 1,585 & 1,527 & 1,431 & $-4.0 \%$ & $-3.7 \%$ & $-3.5 \%$ \\
\hline $\begin{array}{l}K T \text { workforce size at the } \\
\text { end: }\end{array}$ & 538 & 442 & 323 & $-13.5 \%$ & $-18.2 \%$ & $-13.3 \%$ \\
\hline $\begin{array}{l}K C \text { workforce size at the } \\
\text { end: }\end{array}$ & 249 & 264 & 216 & $-9.0 \%$ & $-6.0 \%$ & $-6.0 \%$ \\
\hline $\begin{array}{l}K P \text { workforce size at the } \\
\text { end: }\end{array}$ & 798 & 821 & 892 & $+4.7 \%$ & $+2.1 \%$ & $+2.6 \%$ \\
\hline$\overline{G D}_{0}-\overline{G D}_{8}$ & 0.637 & 0.578 & 0.544 & $-21.0 \%$ & $-19.8 \%$ & $-10.5 \%$ \\
\hline Personnel costs: $\sum_{t \in T} Z_{t}$ & 1,006.5 M€ & $998.8 \mathrm{M} €$ & $984.6 \mathrm{M} €$ & $-1.0 \%$ & $+0.07 \%$ & $-0.5 \%$ \\
\hline
\end{tabular}

Note: Promotion ratio decreases by $5 \%$ yearly.

From Table 10, it is clear that the number of workers in the university becomes reduced when the available personnel budget is low enough to constrain the optimisation of the strategic staff plan. Also, under this circumstance the achievement of the preferable workforce composition is clearly difficult. The latter is deduced from comparing the obtained reductions in average global discrepancy for scenarios 6 and 6'. The ratio capacity/salary for workers within $K P$ is the highest amongst all categories in this university system. Thus, in case of higher reductions in personnel budget, the plan tries to supply the demand with workers in $K P$ whilst the size of the rest of the categories is reduced.

\subsection{Discussion around the impact of academic policies: demand}

The impact assessment in strategic staff plan of considering different trends in demand is based on comparing computational results for scenarios 3, 7 and 8 , according to Table 6 . These results are offered in Table 11. In these scenarios only demand varies in time, leaving the budget and admissible promotional ratios unalterable over time. Doing this, the variability in the obtained results can be directly associated to the variability in demand. 


\section{$22 R$. de la Torre et al.}

Table 11 Impact assessment of required capacity in scenarios 3, 7 and 8

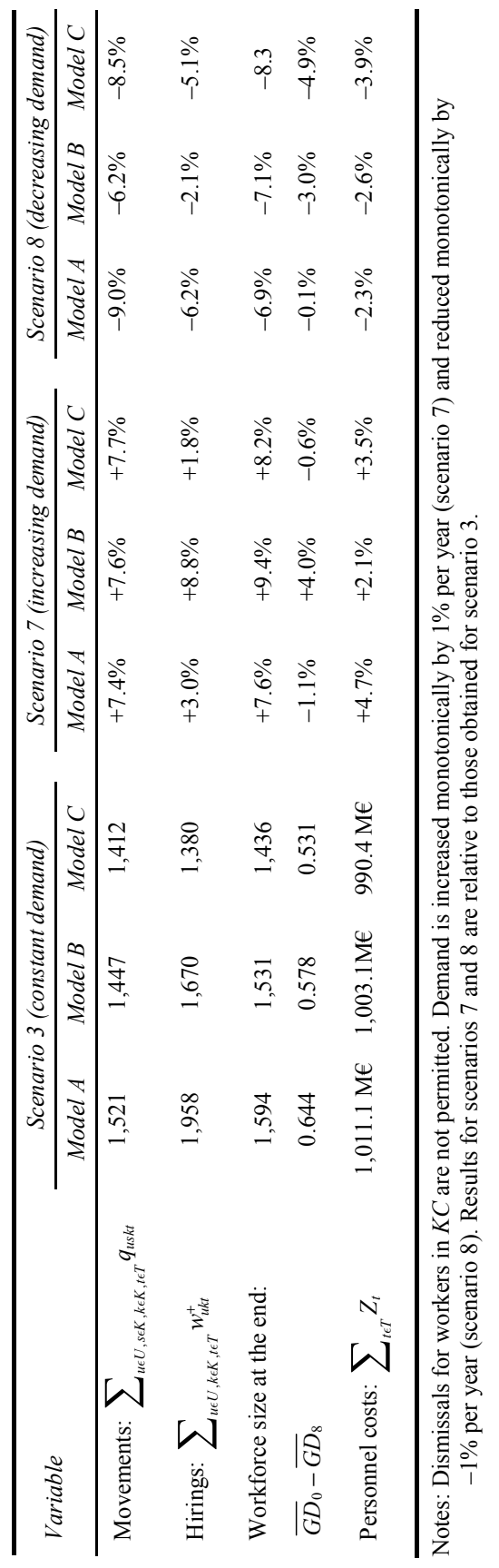


Please consider that results for scenarios 7 and 8 are relative to those obtained for scenario 3. Bearing this in mind, we state that compared to the initial number of workers for the university (1999 workers), at the end of the time horizon the sum of the variables $w_{u k, 8}$ becomes reduced for all university models and scenarios. This reduction in workforce size for all cases shows the current oversizing of the university workforce according to the preferable structure models.

Complementarily, a first insight to the computational results in Table 11 also clearly depicts that all the shown variables for model A present higher values than those for the rest of the models. This fact yields a higher number of promotions, workers hiring from the labour market, workers at the end of the time horizon and the average global discrepancy variation (see results for scenario 3). This happens because model $\mathrm{A}$ is the most different from the current composition of the university.

Addressing now the differences between scenarios, it is interesting to observe that the obtained number of workers at the end of the horizon for any model is also coherent with the considered temporal trends in demand. For instance, given the model A the number of workers at the end of the horizon is increased by $7.6 \%$ in scenario 7 , and decreased down by around $6.9 \%$ for scenario 8 . These results are those envisaged applying the idea that the size of university workforce should be adapted to the volume of activity carried out.

\section{Conclusions}

The main conclusions around the impact that personnel policies concerning contracts have in the determination of the strategic staff plan reveal that the possibility of dismissing workers in categories within $K C$ has a very little influence in the achievement of a preferable workforce composition, for the presented university case. In case dismissals are not permitted, the university takes advantage of other sources of flexibility, like internal promotions. Further, given the priority to internal promotions, the university does not incur in significantly larger costs in personnel management.

In regard of promotion ratio and budget, results yield that by lower values in promotion ratios, the number of internal promotions for workers becomes also diminished, while optimising the strategic staff plan. However, the model adjusts efficiently the workforce composition to the same extent than in the case of considering non-decreasing promotion ratios. Under decreasing promotion ratios, workforce is adjusted emphasising in hiring from labour market and dismissals, when permitted. Moreover, if personnel budgets are reduced in the optimum strategic staff plan, the achievement of a preferable workforce composition results clearly compromised. The strategic staff plan, in this case, determines to increase the weight of workforce within $K P$, since their workers are the most efficient ones in terms of the ratio capacity (teaching hours) per salary received. As a consequence, the weight of workforce in temporal categories diminishes.

The results around academic policies (demand) yield that a sustained increment in demand is directly translated in a higher workforce size. This positive correlation is repeated, as well, in the number of promotions and personnel hired from the labour market throughout the time horizon. Conversely, the university size becomes reduced when sustained reductions in demand happen. These results are those envisaged applying the idea that the university size should be adapted to the volume of activity carried out. 
On the different university models, it is interesting to see that the adjustment in the workforce composition is slower for the university model A than for the models B and C. This happens because the initial composition of university workforce differs much from model $\mathrm{A}$ in the desirable size for categories within $K P$. These categories are almost immovable as their workers are already at the top of the structure and normally leave the organisation just in case of retirement.

\section{Acknowledgements}

This work is supported by the DPI2015-67740-P (MINECO/FEDER) project.

\section{References}

Agasisti, T., Arnaboldi, M. and Azzone, G. (2008) 'Strategic management accounting in universities: the Italian experience', Higher Education, Vol. 55, No. 1, pp.1-15.

Ahn, H-S., Righter, R. and Shanthikumar, J.G. (2005) 'Staffing decisions for heterogeneous workers with turnover', Mathematical Methods of Operations Research, Vol. 62, No. 3, pp.499-514.

ANECA (2014) Agencia Nacional de Evaluación de la Calidad y Acreditación, ANECA website [online] http://www.aneca.es (accessed 20 June 2014).

AQU (2014) Agència per a la Qualitat del Sistema Universitari de Catalunya, AQU website [online] http://www.aqu.cat (accessed 20 June 2014).

Clark, B.R. (1998) Creating Entrepreneurial Universities: Organizational Pathways of Transformation, IAU Press by Pergamon, Oxford.

Clark, B.R. (2003) 'Sustaining change in universities: continuities in case studies and concepts', Tertiary Education and Management, Vol. 9, No. 2, pp.99-116.

Corominas, A., Lusa, A. and Olivella, J. (2012) 'A detailed workforce planning model including non-linear dependence of capacity on the size of the staff and cash management', European Journal of Operational Research, Vol. 216, No. 2, pp.445-458.

de la Torre, R., Lusa, A. and Mateo, M. (2016) 'A MILP model for the long term academic staff size and composition planning in public universities', Omega, Vol. 63, pp.1-11.

Gans, N. and Zhou, Y-P. (2002) 'Managing learning and turnover in the employee staffing', Operations Research, Vol. 50, No. 6, pp.991-1006.

Holt, C.C., Modigliani, F., Muth, J.F. and Simon, H.A. (1960) Planning Production, Inventory and Work Force, Prentice Hall, Englewood Cliffs, NJ.

Hunt, C.M., Oosting, K.W., Stevens, R., Loudon, D. and Migliore, R.H. (1997) Strategic Planning for Private Higher Education, Haworth, Binghamton, NY.

Lillis, D. (2006) 'The systematic evaluation of a strategic management program in an Irish Institute of Technology', Tertiary Education Management, Vol. 121, No. 3, pp.241-256.

Lounsbury, M. (2001) 'Institutional sources of practice variation: staffing college and university recycling programs', Administrative Science Quarterly, Vol. 46, No. 1, pp.29-56.

Machuca, J.A.D., González-Zamora, M.M. and Aguilar-Escobar, V.G. (2006) 'Service operations management research', Journal of Operations Management, Vol. 25, No. 3, pp.585-603.

Martinez, M.C. and Wolverten, M. (2009) Innovative Strategy Making in Higher Education, IAP - Information Age Publishing, Charlotte, NC.

McKelvey, M. and Holmen, M. (2009) Learning to Compete in European Universities: From Social Institution to Knowledge Business, Edward Elgar Publishing Limited, Cheltenham, UK. 
Ministry - Ministerio de Educación, Cultura y Deporte (2014) 'Ministry website' [online] http://www.mecd.gob.es (accessed 17 September 2014).

Roth, A.V. and Menor, L.J. (2003) 'Insights into service operations management: a research agenda', Production and Operations Management, Summer, Vol. 12, No. 2, p.145, ABI/INFORM Complete.

Rowley, D.J. and Sherman, H. (2001) From Strategy to Change: Implementing the Plan in Higher Education, Jossey-Bass Publishers, San Francisco, CA.

Santiago, P., Brunner, J.J., Haug, G., Malo, S. and Pietrogiacomo, P. (2009) OECD Reviews of Tertiary Education, OECD, Spain; Paris.

Shattock, M. (2003) Managing Successful Universities, Society for Research in Higher Education \& Open University Press, London, UK.

Singhal, K. (1992) 'A noniterative algorithm for the multiproduct production and work force planning problem', Operations Research, Vol. 40, No. 3, pp.620-625.

Song, H. and Huang, H-C. (2008) 'A successive convex approximation method for multistage workforce capacity planning problem with turnover', European Journal of Operational Research, Vol. 188, No. 1, pp.29-48.

Titova, N. and Shutov, A. (2014) 'Predictive model of strategic development of a university', Procedia Computer Science, Vol. 31, pp.459-467.

UPC - Universitat Politècnica de Catalunya BarcelonaTech (2014) 'UPC website' [online] http://www.upc.edu (accessed 14 March 2014). 